\title{
Leishmaniosis visceral en un paciente con infección por VIH
}

\author{
Pilar Olea
}

Hospital de Enfermedades Infecciosas Dr. Lucio Córdova.

Recibido: 6 de abril de 2012 Aceptado: 14 de diciembre de

Correspondencia a: Pilar Olea M. pilaroleam@gmail.com

\section{Introducción}

$\mathrm{L}$ a leishmaniosis es una infección crónica causada por un protozoo intracelular del género Leishmania y transmitida por mosquitos hematófagos. Afecta en forma endémica a países de Asia especialmente el subcontinente indio, África, Latinoamérica y la cuenca mediterránea ${ }^{1}$. Existen variadas formas de presentación en el hombre siendo tres las principales: leishmaniosis cutánea, mucosa y visceral ${ }^{2,3}$. Esta última es la más grave y letal y puede afectar tanto a pacientes inmunocompetentes como inmunocomprometidos. Se considera que por cada infección clínica existen 30 a 100 casos subclínicos ${ }^{1}$. En los pacientes con infección por VIH con inmunocompromiso grave, la leishmaniosis visceral (LV) se presenta como una infección oportunista y en España, por ejemplo, llegó a ser la cuarta enfermedad más frecuente con que debutaba el SIDA antes del inicio de la terapia antirretroviral (TARV) de alta eficacia ${ }^{4}$. Las especies más frecuentemente involucradas en LV son: Leishmania donovani en Asia y África, Leishmania chagasi en Latinoamérica y Leishmania infantum en países del Mediterráneo ${ }^{1}$. En Latinoamérica sólo Uruguay y Chile están libres de la infección por este microorganismo por carecer del vector que la transmite. Sin embargo, debido a la facilidad con que las personas se trasladan actualmente entre países y continentes, solemos enfrentarnos a pacientes con infecciones que nos son ajenas y que resultan de difícil diagnóstico, como la leishmaniosis. Se presenta el caso clínico de un paciente con LV e infección por VIH atendido en el Hospital de Enfermedades Infecciosas Dr. Lucio Córdova en Santiago de Chile.

\section{Caso clínico}

Varón de 50 años, heterosexual, con antecedente de consumo de alcohol y drogas no intravenosas. Había vivido en España por 25 años hasta dos años antes. No refería otras patologías personales ni familiares relevantes.

Tenía historia de compromiso del estado general progresivo, pérdida de peso y sudoración. Al tercer mes de evolución se agregó fiebre intermitente y deposiciones diarreicas por lo cual consultó por primera vez, en un centro asistencial privado. En ese momento destacaba al examen físico una hepato-esplenomegalia. Entre los exámenes de laboratorio, la serología para VIH resultó positiva, con un recuento de linfocitos CD4 de 24 céls/ $\mathrm{mm}^{3}$ y pancitopenia en el hemograma. Se solicitó una TAC de abdomen que confirmó la existencia de hepatoesplenomegalia, además de múltiples adenopatías mesentéricas y retroperitoneales. Inició TARV con lamivudina, tenofovir y efavirenz, aparentemente con buena tolerancia y adherencia. Se derivó al Hospital Dr. Lucio Córdova para continuar estudio y tratamiento. Ingresó en regulares condiciones generales, subfebril, pálido y enflaquecido. Presentaba una gran esplenomegalia de consistencia blanda, un hígado a 4-5 cm bajo el reborde costal y una 
adenopatía inguinal de $1 \mathrm{~cm}$ de diámetro. Se internó con los diagnósticos de infección por VIH en TARV y hepatoesplenomegalia en estudio.

Dentro de los exámenes destacaba una anemia con hematocrito de 23,2\% y hemoglobina de 7,3 g/dl, leucopenia de $680 / \mathrm{mm}^{3}$, RAN de $330 / \mathrm{mm}^{3}$, plaquetas $109.000 / \mathrm{mm}^{3}$, VHS $121 \mathrm{~mm} / 1^{\circ} \mathrm{h}$ y PCR 70,6 mg/L. La función renal, hepática, así como la deshidrogenasa láctica, amilasa y lipasa fueron normales. El perfil proteico y la electroforesis de proteínas evidenció una hipergammaglobulinemia difusa intensa y una hipoalbuminemia moderada. La $\beta 2$ microglobulina estaba elevada $(8,1 \mathrm{mg} / \mathrm{L})$. La serología para Toxoplasma resultó positiva a títulos de 1/1.024. El recuento de CD4 en ese momento era de 35 céls $/ \mathrm{mm}^{3}$ y la carga viral de 12.000 copias/ml. Los hemocultivos corrientes y para micobacterias así como las baciloscopias y cultivos de Koch de expectoración resultaron negativos. El VDRL fue no reactivo, el HBsAg y VHC también fueron negativos. Fue evaluado por oftalmólogo quien encontró un fondo de ojo normal.

El paciente se mantuvo afebril, con buen ánimo y apetito, sin molestias específicas, pero inquieto y algo angustiado por su situación de salud. Hasta ese momento se había mantenido en tratamiento con lamivudina, tenofovir, efavirenz y con profilaxis de infecciones oportunistas.

Dentro del estudio se realizó además una biopsia de médula ósea y del ganglio femoral. Aproximadamente al mes de hospitalización, se recibió el resultado de la biopsia de médula ósea que describía: "gran cantidad de histiocitos con citoplasma ocupado por múltiples estructuras puntiformes basófilas que corresponden a amastigotes redondos ovales con el núcleo en la mitad posterior del organismo y el quinetoplasto en la anterior". Concluyó que los hallazgos eran compatibles con compromiso medular por leishmaniosis. La biopsia del ganglio inguinal fue informada como una hiperplasia folicular.

Con el diagnóstico de leishmaniosis visceral se inició tratamiento con anfotericina B deoxicolato $1 \mathrm{mg} / \mathrm{kg} / \mathrm{día}$ por 14 días, con una relativa buena tolerancia, presentando una alza discreta de parámetros nitrogenados hacia el final del tratamiento y flebitis. Además necesitó transfusión de glóbulos rojos y aporte de potasio.

El paciente evolucionó con escasa sintomatología, pero con una carga viral en ascenso (35.000 copias/ml). Ante el fracaso de la TARV que estaba recibiendo, y frente a la posibilidad de que el tratamiento con anfotericina también fracasara por la grave inmunosupresión del paciente, se decidió cambio de terapia a didanosina, atazanavir, ritonavir y raltegravir (sin genotipificación previa y con aprobación posterior del Ministerio de Salud).

Al finalizar 14 días de tratamiento con anfotericina se dio alta hospitalaria con el compromiso, por parte del paciente, de mantener una buena adherencia a la TARV, no consumir drogas ni alcohol, acudir a los controles médicos que se le indicaran y con la posibilidad de realizar un segundo curso de tratamiento con anfotericina cuando su recuento de CD4 hubiese aumentado. En ese momento el paciente se encontraba en relativas buenas condiciones generales y la esplenomegalia había disminuido considerablemente. El hemograma mostraba persistencia de la anemia con hematocrito de $21,1 \%$ y hemoglobina de 7,2 $\mathrm{g} / \mathrm{dl}$, mejoría relativa de los leucocitos, que habían aumentado a $1730 / \mathrm{mm}^{3}$ con RAN de 1.228 y plaquetas $126.000 /$ $\mathrm{mm}^{3}$. La TAC de tórax fue normal y la TAC de abdomen y pelvis fue similar a la del ingreso. La biopsia ganglionar que había sido informada en primera instancia sólo como hipertrofia folicular, fue revisada por el patólogo con el diagnóstico de LV, y también se encontraron estructuras basofílicas al interior de histiocitos que correspondían a amastigotes de Leishmania.

El paciente se mantuvo en control ambulatorio refiriendo que se sentía bien y que mantenía una buena adherencia a la TARV. Al mes del cambio de terapia antirretroviral tenía una carga viral indetectable y un aumento de CD4 a $82 \mathrm{cél} / \mathrm{mm}^{3}$. Sin embargo, a los dos meses del alta el bazo había aumentado nuevamente de tamaño, el hemograma se había deteriorado en forma significativa y una nueva biopsia de médula ósea mostró presencia del parásito, por lo que se diagnosticó una LV reactivada. Recibió un nuevo tratamiento con anfotericina $\mathrm{B}$ deoxicolato que, en esta oportunidad, recibió por 21 días y continuó con profilaxis secundaria con una dosis de $50 \mathrm{mg}$ cada 14 días. Al finalizar el segundo tratamiento el paciente se encontraba asintomático, había disminuido la esplenomegalia y aumentado los leucocitos y plaquetas. Con posterioridad el paciente ha continuado en control ambulatorio, con buena adherencia al tratamiento, realizando sus actividades normales, sin esplenomegalia, con un hemograma dentro de límites normales y sin recaída de la LV por 29 meses.

\section{Discusión}

La leishmaniosis visceral es producida por un protozoo intracelular estricto que transmite la hembra de mosquitos Phlebotomus en Europa, Asia y África y Lutzomyia en Latinoamérica. En el caso de L. infantum y L. chagasi el reservorio es una gran variedad de mamíferos silvestres y domésticos como perros, roedores, vacunos y el hombre. Para L. donovani, en cambio, sólo se ha identificado como reservorio al hombre ${ }^{1}$. En el momento de alimentarse, el mosquito succiona sangre con los macrófagos infectados por el parásito el cual va a alojarse en su intestino y allí se multiplica en la forma flagelar o promastigote. Al volver a picar a un mamífero el parásito se introduce a través de la piel migrando luego al interior de los macrófagos, evadiendo de esta forma la actividad inmunológica inespecífica del huésped. En el interior de esta célula el 
parásito es incorporado en una vacuola que luego se une al lisosoma donde sería destruido, de no ser porque el parásito vira al estado de amastigote que es resistente a las enzimas del lisosoma. Allí se multiplica hasta que el macrófago muere y los parásitos son liberados y van a infectar a otras células, diseminándose de esta forma en el sistema retículoendotelial ${ }^{3}$.

La evolución que tenga esta infección dependerá en gran parte de la especie de Leishmania involucrada y de la respuesta inmunológica del huésped, específicamente de la inmunidad celular por tratarse de un parásito intracelular estricto. Si la respuesta es de predominio Th1 se producirán IL 2 y 12 e interferón gama, que tienen un efecto protector pues activan a los macrófagos aumentando la muerte intracelular del parásito. Por el contrario, si la respuesta es del tipo Th2 se producen IL 4 y 10 que se relacionan con progresión de la infección. En los pacientes con infección por VIH la respuesta Th1 está gravemente disminuida y la infección por Leishmania produce aumento de la respuesta del tipo Th2 lo cual produce aumento de la replicación viral y disminución de los CD4. De este modo la coinfección $\mathrm{VIH} /$ Leishmania produce progresión mutua de ambas enfermedades ${ }^{4,5}$.

En los pacientes con SIDA que viven en áreas endémicas, la posibilidad de presentar LV es 100 a 1.000 veces mayor que en población general, ya sea por reactivación de una infección crónica o por una infección reciente ${ }^{4}$. En ellos se comporta como una infección oportunista de la etapa SIDA y a pesar de que en la actualidad no se considera dentro de las patologías definitorias de este estado se ha sugerido, por parte de algunos especialistas, que debiera ser incluida ${ }^{5}$.

La respuesta humoral a la infección puede medirse con fines diagnósticos pero en los pacientes con infección por VIH ésta es muy irregular y se cree que depende del momento en que se adquiere la infección. Si la adquisición de la Leishmania se produce antes que el SIDA habrá respuesta de anticuerpos, pero si se contrae después es probable que no se detecten ${ }^{3}$.

El período de incubación es de 4 a 10 meses, al cabo de los cuales el paciente comenzará con fiebre irregular persistente, compromiso del estado general y baja de peso. También pueden presentarse síntomas digestivos como diarrea, dolor abdominal y, con menos frecuencia, síntomas respiratorios como tos. Al examen físico destacan la desnutrición, anemia, hepatomegalia y especialmente esplenomegalia. También pueden encontrarse adenopatías cervicales pequeñas a medianas de características inflamatorias. Entre los exámenes de laboratorio destaca el hemograma con pancitopenia y en las imágenes se confirma la hepato-esplenomegalia, como también pueden visualizarse adenopatías intraabdominales.

El cuadro clínico en los pacientes con infección con $\mathrm{VIH}$ no difiere sustancialmente del que presentan los pacientes inmunocompetentes, pero presenta la dificultad de diagnóstico diferencial con una serie de otras patologías oportunistas que pueden dar síntomas similares. $\mathrm{Su}$ respuesta al tratamiento es menor y presentan un alto porcentaje de recaídas $(65 \%)$, especialmente durante el primer año post tratamiento ${ }^{5}$.

Un cuadro clínico como el descrito en un paciente que vive o ha vivido en una zona endémica de leishmaniosis debe hacer plantear esta hipótesis diagnóstica, la cual se debe confirmar con el hallazgo del parásito en tejidos o sangre. En la actualidad el examen de elección es la biopsia de médula ósea con estudio histológico y cultivo que tienen un rendimiento de 38 a $80 \%$ y 50 a $100 \%$, respectivamente ${ }^{5}$. El cultivo se realiza en agar sangre o en medios selectivos como el Novy-Mc Neal-Nicolle (NNN) a $24-26^{\circ} \mathrm{C}$. Se debe incubar por 4 sem, pero ya a los 14 días se puede detectar el parásito en su forma de promastigote $^{3}$. El cultivo de sangre periférica también es útil, especialmente si se realiza de la capa leucocitaria, y tiene la ventaja de ser un examen mucho más sencillo y no invasor que se puede realizar en lugares que no disponen de las facilidades para hacer biopsia. Lo mismo ocurre con el examen directo del frotis de sangre periférica que puede tener un buen rendimiento (50-68\%), pero que requiere de personas expertas para su realización ${ }^{4}$. En los tejidos se aprecian los amastigotes, forma aflagelar ovoidea con un núcleo al interior de las células. La biopsia esplénica tiene un alto rendimiento pero se ha dejado de lado por ser un procedimiento invasor de mayor riesgo que la biopsia de médula ósea. Se pueden estudiar también otros tejidos como hígado, ganglios, lesiones de mucosa gastrointestinal, etc.

La RPC es un examen que ha mostrado tener alta sensibilidad, hasta $97 \%$ en sangre periférica y $100 \%$ en médula ósea. Se ha demostrado útil en el control de tratamiento especialmente en los pacientes con infección por VIH, que tiene tendencia a recaer, evitando así la repetición de métodos invasores diagnósticos ${ }^{6}$. Tiene el inconveniente de no estar disponible en la mayoría de los países en que la leishmaniosis es un problema endémico, por su alto costo, y de no permitir el estudio simultáneo de otros posibles patógenos como ocurre con la biopsia ${ }^{4}$. Esto último es muy importante sobre todo en los pacientes con VIH que pueden presentar co-infecciones con otros agentes oportunistas cuyos síntomas pueden sobreponerse, enmascararse o potenciarse entre sís-7.

El paciente presentado tenía un síndrome febril prolongado, forma frecuente de presentación de esta enfermedad, que comenzó con compromiso del estado general y baja de peso y continuó con sensación febril y diarrea. Esta sintomatología lo llevó a consultar y a que se determinara su condición de infección por VIH. El resto del estudio reveló una pancitopenia, hepato-esplenomegalia y adenopatías intraabdominales e inguinal. Se plantearon las hipótesis 
diagnósticas de síndrome febril prolongado en estudio, linfoma, micobacteriosis y, por el antecedente de haber vivido largo tiempo en España, también leishmaniosis. Se le realizó la biopsia de médula ósea con estudio histológico que reveló el diagnóstico pero no se le hizo cultivo por carecer de experiencia en el tema. Cabe destacar la dificultad que puede existir para reconocer el parásito en un país en que no presenta la enfermedad, ya que en una primera observación no se visualizaron los amastigotes en la biopsia ganglionar, lo que si se logró en una segunda mirada cuando ya se tenía el diagnóstico.

La hipergamablobulinemia y el alza de $\beta 2$ microglobulina que presentaba este paciente también están descritas en $\mathrm{LV}^{2,5}$.

En la actualidad se dispone de dos tipos de medicamentos, con evidencias de efectividad para el tratamiento de la LV: los antimoniales pentavalentes y las distintas formas de presentación de la anfotericina, ambos con los inconvenientes de ser de administración parenteral y tener frecuentes y potencialmente efectos adversos graves.

La anfotericina B deoxicolato puede producir hipersensibilidad, flebitis de las vías venosas de infusión, hipopotasemia y toxicidad renal. Esta última puede prevenirse o minimizarse con la administración simultánea o previa de solución salina al 0,9\% y un tiempo prolongado de infusión del medicamento ${ }^{3}$. La dosis recomendada depende de la especie de Leishmania, en el caso de $L$. infantum es de $1 \mathrm{mg} / \mathrm{kg} /$ día (máximo $50 \mathrm{mg} /$ día), hasta la mejoría sintomática que debería ocurrir con una dosis total acumulada de 1 a 1,5 $\mathrm{gr}^{4}$.

La anfotericina liposomal (AmBisome $\left.{ }^{\circledR}\right)$ presenta menos efectos adversos, especialmente en lo que se refiere a toxicidad renal, pero tiene un costo extremadamente alto. La dosis para LV en países del Mediterráneo es de $20-$ $21 \mathrm{mg} / \mathrm{kg}$ iv como dosis total a administrar en diversos esquemas que van desde 2 a 7 días $^{8-12}$.

En tanto, los antimoniales pentavalentes presentan menor toxicidad renal, pero pueden producir pancreatitis, toxicidad cardíaca, reacciones alérgicas y molestias digestivas $^{2,13}$. Adicionalmente tienen el problema de aparición de resistencia del parásito a éste fármaco, en especial en India y otros países asiáticos ${ }^{2}$.

La miltefosina es el único medicamento de uso oral que ha demostrado ser exitoso para el tratamiento de la LV en Asia, pero tiene mala tolerancia digestiva con un alto porcentaje de pacientes que presentan vómitos. No existe mayor experiencia en el tratamiento con miltefosina de LV por L. infantum ni en pacientes con infección por $\mathrm{VIH}^{4,14}$. Ninguno de estos dos últimos medicamentos está disponible en Chile en la actualidad.

El mejor tratamiento para la LV está aún por determinar y probablemente deba ser personalizado, dependiendo del paciente y de la especie de Leishmania involucrada. Sin embargo, la anfotericina, en cualquiera de sus presentacio- nes, constituye el tratamiento más utilizado en los países del Mediterráneo, tanto en pacientes inmunocompetentes como en aquellos con infección por VIH, que presentan infección por $L$ infantum.

Una vez finalizado el tratamiento en los pacientes coinfectados con VIH, se sugiere mantener una profilaxis secundaria hasta que la terapia antirretroviral logre que los linfocitos CD4 aumenten sobre 350, la replicación viral esté controlada y, además, el paciente se haya mantenido al menos un año sin recaída ${ }^{4,15,16}$. En el caso de utilizarse anfotericina B, la dosis recomendada es de $50 \mathrm{mg}$ iv al mes, mientras que para la forma liposomal es de $3-5 \mathrm{mg}$ / $\mathrm{kg}$ iv cada 2 a 4 sem.

El paciente presentado recibió anfotericina B sin mayores efectos adversos, a excepción de flebitis de las vías venosas de infusión que fue bien controlado con la administración de hidrocortisona. Tuvo un primer tratamiento de 14 días que controló parcial y temporalmente la infección. Habiendo iniciado TARV se le administró un segundo tratamiento, esta vez por 21 días, seguido de profilaxis secundaria cada dos semanas, que lo ha mantenido sin recaídas por 29 meses. En la medida que el paciente restaure inmunidad se irá modificando esta profilaxis de modo que llegue a recibirla cada 28 días, como sugieren los especialistas españoles.

En relación a la profilaxis primaria en zonas endémicas, en la actualidad sólo se dispone de medidas para la protección contra la picadura de mosquitos ya sea por medios mecánicos (mosquiteros, ropa adecuada) o químicos (repelentes de mosquitos), ya que no existe vacuna para la leishmaniosis y es prácticamente imposible eliminar el vector y tratar los reservorios animales ${ }^{1}$.

Investigadores en el tema consideran que el avance en nuevas, mejores y más baratas alternativas de tratamiento $\mathrm{y}$ de profilaxis han sido extremadamente lentas y lo atribuyen al escaso interés de los laboratorios en esta y otras enfermedades, como malaria, que afectan principalmente a países pobres ${ }^{1}$.

\section{Resumen}

La leishmaniosis es una infección producida por parásitos del género Leishmania, transmitida por mosquitos hematófagos. Puede ocasionar infecciones subclínicas o manifestarse con compromiso cutáneo, mucoso o visceral. Esta última forma de presentación, que constituye la leishmaniosis visceral, es la más grave pudiendo llegar a ser fatal y en los pacientes con infección por VIH se presenta como una infección oportunista de difícil diagnóstico y tratamiento. Se reporta el caso de un paciente con infección por VIH con leishmaniosis visceral cuyo cuadro clínico se presentó como un síndrome febril prolongado con hepato-esplenomegalia, linfadenopatías y 
pancitopenia. Se plantearon los diagnósticos diferenciales de linfoma y otras infecciones oportunistas, como micobacteriosis. La demostración de amastigotes del parásito en el aspirado de médula ósea confirmó el diagnóstico. El paciente se trató con anfotericina $\mathrm{B}$ deoxicolato por 14 días y a los 2 meses presentó una recaída por lo cual recibió un segundo curso con el mismo medicamento por 21 días y se mantuvo posteriormente con profilaxis secundaria. Además se realizó cambio de la TARV por fracaso virológico e inmunológico. Ha continuado controlándose en forma ambulatoria por 29 meses presentando evolución satisfactoria, sin nuevas recaídas.

\section{Referencias bibliográficas}

1.- Guerin P J, Olliaro P, Sundar S, Boelaert M, Croft S L, Desjeux P, et al. Visceral leishmaniasis: current status of control, diagnosis, and treatment, and a proposed research and development agenda. Lancet Infect Dis 2002; 2: 494-501.

2.- Weina P J, Neafie R C, Wortmann G, Polhemus M, Aronson N E. Old world leishmaniasis: an emerging infection among deployed US military and civilian workers. Clin Infect Dis 2004; 39: 1674-80.

3.- Ampuero J. Leishmaniasis. Módulos técnicos, serie documentos monográficos $\mathrm{N}^{\circ} 8$ Lima 2000. Disponible en: http://bvs.minsa.gob.pe/ local/OGEI/795_MS-OGE106.pdf Accedido: 30 de enero de 2012.

4.- Pineda J, Macías J, García J. Leishmaniasis e infección por VIH. Disponible en: www.saei. org/hemero/libros/c25.pdf Accedido: 30 de enero de 2012.

5.- Pintado V, López-Vélez R. HIV-associated visceral leishmaniasis. Clin Microbiol Infect 2001; 7: 291-300.

6.- Pizzuto M, Piazza M, Senese D, Scalamogna C, Calattini S, Corsico L, et al. Role of PCR in diagnosis and prognosis of visceral leishmaniasis in patients coinfected with human inmunodeficiency virus type 1 . J Clin Microbiol 2001; 39: 357-61.

7.- Laguna F, Adrados M, Alvar J, Soriano V, Valencia M E, Moreno V, et al. Visceral leishmaniasis in patients infected with the human inmunodeficiency virus. Eur J Clin Microbiol Infect Dis 1997; 16: 898-903.

8.- Syriopoulou V, Daikos G L, Theodoridou M, Pavlopoulou I, Manolaki A G, Sereti E, et al. Two doses of a lipid formulation of amphotericin B for the treatment of Mediterranean visceral leishmaniasis. Clin Infect Dis 2003; 36: 560-6.

9.- Meyerhoff A. US Food and Drug Administration approval of AmBisome (liposomal amphotericin B) for the treatment of visceral leishmaniasis. Clin Infect Dis 1999; 28: 42-8.

10.- Davidson R N, di Martino L, Gradoni L, Giacchino R, Gaeta G B, Pempinello R, et al. Short course treatment of visceral leishmaniasis with liposomal amphotericin B (AmBisome). Clin Infect Dis 1996; 22: 938-43.

11.- Sundar S, Mehta H, Suresh A V, Singh S P, Rai M, Murray H W. Amphotericin B treatment for Indian visceral leishmaniasis: conventional versus lipid formulations. Clin Infect Dis 2004;
38: 377-83.

12.- Sundar S, Mehta H, Chhabra A, Singh V, Chauhan V, Desjeux P, et al. Amphotericin B colloidal dispersion for the treatment of Indian visceral leishmaniasis. Clin Infect Dis 2006; 42: 608-13.

13.- Laguna F, López-Vélez R, Pulido F, Salas A, Torre-Cisneros J, Torres E, et al. Treatment of visceral leishmaniasis in VIH-infected patients: a randomized trial comparing meglumine antimoniate with amphotericin B. AIDS 1999; 13: 1063-9.

14.- Sundar S, Rosenkaimer F, Makharia M K, Goyal A K, Mandal A K, Voss A, et al. Trial of oral miltefosine for visceral leishmaniasis. Lancet 1998; 352: 1821-3.

15.- De la Rosa R, Pineda JA, Delgado J, Macías J, Morrillas F, Mira J A, et al. Incidence of and risk factors for symptomatic visceral leishmaniasis among human immunodeficiency virus typo 1 infected patients from Spain in the era of highly active antirretroviral therapy. J Clin Microbiol 2002; 40: 762-7.

16.- Ribera E, Ocaña I, de Otero J, Cortés E, Gasser I, Pahissa A. Prophylaxis of visceral leishmaniasis in human inmmunodeficiency virus infected patients. Am J Med 1996; 100: 496-501. 